\title{
miR-196a-5p modulates gastric cancer stem cell characteristics by targeting Smad4
}

\author{
YUNZHI PAN, XIONG SHU, LICHAO SUN, LONG YU, LIXIN SUN, ZHIHUA YANG and YULIANG RAN \\ National Cancer Center/Cancer Hospital, Chinese Academy of Medical Sciences \\ and Peking Union Medical College, Chaoyang, Beijing 100021, P.R. China
}

Received November 22, 2016; Accepted April 5, 2017

DOI: $10.3892 /$ ijo.2017.3965

\begin{abstract}
Cancer stem cells (CSCs) are undifferentiated cancer cells with a high tumorigenic activity, the ability to undergo self-renewal, and a multilineage differentiation potential. Clinical evidence suggests that CSCs in a tumor mass are the cellular determinants to promote cancer invasion and metastasis. MicroRNAs (miRNAs) have emerged as important modulators of cancer stem cell characteristics. Unveiling the candidate miRNAs that regulate CSCs may provide novel therapeutic targets against cancer. We analyzed the miRNA expression profiles regulating the cancer stem-like cell characteristics in gastric cancer. Gastric cancer stem cells (GCSCs) were sorted using the stem cell marker CD44 by fluorescence-activated cell sorting. Functional studies revealed that CD44(+) cells formed more sphere colonies and showed higher invasiveness than CD44(-) cells. miRNA microarray analysis revealed that miR-196a-5p was significantly upregulated in CD44(+) cells than CD44(-) cells. Suppression of miR-196a-5p led to decreased colony formation and invasion of GCSCs. miR-196a-5p decreased the expression of Smad4 by targeting 3'-UTR of the mRNA. The expression of Smad4 in gastric cancer tissues was correlated with differentiation state of tumors, TNM stage and depth of invasion. The stimulation of epithelial-mesenchymal transition (EMT) by miR-196a-5p in cancer stem-like cells was abolished by overexpression of Smad4. Collectively, these data demonstrate that miR-196a-5p has a key role in EMT and invasion by targeting Smad4 in GCSCs. miR-196a-5p may serve as a potential target for gastric cancer therapy.
\end{abstract}

\section{Introduction}

Gastric cancer is one of the most aggressive malignancies. It has the second highest mortality rate among cancers and is

Correspondence to: Dr Yuliang Ran, National Cancer Center/Cancer Hospital, Chinese Academy of Medical Sciences and Peking Union Medical College, 17 Panjiayuan Subdistrict, Chaoyang, Beijing 100021, P.R. China

E-mail: ran_yuliang@126.com

Key words: gastric cancer stem cells, miR-196a-5p, Smad4, invasion the fourth most common cancer in the world $(1,2)$. Over the past decades, numerous efforts have been made in improving the treatment of gastric cancer, but unfortunately the outcome has been disappointing (3). Emerging evidence suggests that the existence of cancer stem cells (CSCs) could play pivotal roles in cancer progression and treatment resistance in gastric cancer $(4,5)$. CSCs, being the small proportion of cancer cells, have powerful self-renewal capacity and the potential to differentiate into any cells in the tumor population, and are responsible for the resistance to chemotherapy and radiation (6). Additionally, CSCs are considered to be the most important source of tumor invasion and metastasis.

CSCs have been successfully identified in a variety of cancers including breast, brain, colon, and gastric cancer (7-10). Consequently, numerous therapeutic approaches targeting CSCs have been proposed (11-15). One of the effective strategies for the identification and elimination of CSCs is to target several cell surface markers overexpressed in CSCs $(16,17)$. Elevated expression of these cell surface markers including CD44, CD133, CD123, EpCAM (CD326) (18-20) was correlated with different clinical significance such as clinical phenotype and prognosis. CD44 is a transmembrane glycoprotein and used to isolate CSCs in various cancers, especially in gastric cancer $(21,22)$.

Epithelial-mesenchymal transition (EMT) plays critical roles not only in tumor metastasis but also in recurrence. In the EMT process, the expression of E-cadherin is downregulated, while the expression of the mesenchymal molecules such as vimentin and $\mathrm{N}$-cadherin are upregulated. In addition, increasing evidence implicates that EMT-type tumor cells share various biological characteristics with CSCs. Importantly, microRNAs (miRNAs) can serve as the key molecule in the EMT and some other biological and pathologic processes.

miRNAs are endogenous and small non-coding RNA molecules ( $22 \mathrm{nt})$ that negatively regulate gene expression by targeting mRNAs posttranscriptionally. miRNAs bind to the partially complementary target sites in 3'-untranslated region (3'-UTRs) of mRNA, inducing mRNA degradation or translational inhibition. To date, abnormal expression of miRNAs has been identified in various kinds of malignancies, which can function as either oncogenes or tumor suppressor genes. Moreover, miRNAs play an important role in modulating CSCs properties such as self-renewal capacity, migration and invasion $(23,24)$. miR-200c overexpression inhibits 
chemoresistance, invasion and colony formation in pancreatic CSCs (25). The miR-106b family is overexpressed in several tumors including gastric cancer, which could regulate CSC properties, particularly EMT characteristics through the TGF- $\beta$ signaling pathway (26). miR-19b/20a/92a regulates the self-renewal ability and proliferation of GCSCs (27).

In this study, we have identified CSCs phenotypes in CD44(+) stem-like cells in gastric cancer. Then we analyzed the miRNA expression profiles between CD44(+) and CD44(-) gastric cells to explore molecular mechanisms related to CSCs characteristics. Our data demonstrated that upregulated miR-196a-5p markedly promoted invasion and contributed to stem cell-like phenotypes in GCSCs by targeting Smad4 and mediating TGF- $\beta$-induced EMT. As a novel miRNA, miR-196a-5p can modulate gastric cancer stem cell-like characteristics and may be a potential target for gastric cancer therapy.

\section{Materials and methods}

Cell lines and cancer stem cell culture. The human gastric SNU-5 and BGC-823 cell lines were purchased from the Chinese Academy of Sciences Cell Bank. SNU-5 gastric cancer cells were maintained in RPMI-1640 medium (Thermo Fisher Scientific, USA) supplemented with $10 \%$ FBS (Thermo Fisher Scientific), 1\% L-glutamine (Gibco, Grand Island, NY, USA) and $1 \%$ penicillin-streptomycin sulfate (Thermo Fisher Scientific). BGC-823 gastric cancer cells were maintained in DH medium (Thermo Fisher Scientific) supplemented with 10\% FBS (Thermo Fisher Scientific), 1\% L-glutamine (Gibco) and $1 \%$ penicillin-streptomycin sulfate (Thermo Fisher Scientific).

The serum-free medium (SFM) was composed of DMEM/F12, $20 \mu \mathrm{l} / \mathrm{ml}$ B27 supplement (Life Technologies), $20 \mathrm{ng} / \mathrm{ml}$ basic fibroblast growth factor (bFGF, Gibco), $10 \mathrm{ng} / \mathrm{ml}$ EGF (Gibco) and LIF (Gibco). GCSCs were isolated from SNU-5 or BGC-823 cell line by using SFM. These cells can form sphere-like cell aggregates in less than 7 days. All cultures were maintained in a $37^{\circ} \mathrm{C}$ incubator supplemented with $5 \% \mathrm{CO}_{2}$.

Flow cytometry analysis and fluorescence-activated cell sorting. GCSCs were isolated from SNU-5 or BGC-823 cell line by using SFM in less than 7 days. The cells were stained with a 400-fold dilution of anti-CD44-FITC (BD Biosciences) and incubated for $1 \mathrm{~h}$ at $4^{\circ} \mathrm{C}$. Then the cells were washed with PBS. Finally, they were analyzed and sorted immediately with fluorescence-activated cell sorting (FACS) AriaIII (BD Biosciences).

miRNA microarray. Total RNAs of CD44(+) and CD44(-) SNU-5 cells were prepared using TRIzol reagent (Invitrogen) according to the manufacturer's instructions. Microarray was performed using the Affymetrix GeneChip miRNA 2.0 platform (CapitalBio Technology, China). The comparative analysis between the CD44(+) sample and CD44(-) sample was carried out using fold-change, and miRNA with 2-fold change in expression were considered differentially regulated. Hierarchical cluster analysis was performed using complete linkage and Euclidean distance as a measure of similarity.
Quantitative real-time PCR ( $q R T-P C R)$. The first-strand cDNA was synthesized using iscript cDNA synthesis kit (Bio-Rad, USA) according to the manufacturer's instructions. Quantitative real-time PCR analyses were carried out with a PCR mixture containing $1 \mu \mathrm{mol} / 1$ of each primer and EvaGreen Supermix (Bio-Rad). The amplifications were performed at $95^{\circ} \mathrm{C}$ for $15 \mathrm{sec}$ and at $60^{\circ} \mathrm{C}$ for $30 \mathrm{sec}$ using a StepOnePlus real-time PCR system (Applied Biosystems). Each sample was examined in triplicate and the mRNA level of GAPDH was used as an internal control. Primer sequences are listed in Table I.

To confirmed expression of miR-196a-5p, real-time qPCR was performed. Total RNA was extracted from culture cells using mirVana miRNA isolation kit (Ambion). miRNAs expression was measured using Bulge-Loop miRNA qRT-PCR Primer Set (Ribobio Co., Guangzhou, China) and qRT-PCR Starter kit. The amplifications were performed at $95^{\circ} \mathrm{C}$ for $20 \mathrm{sec}$, followed by 40 cycles of amplication at $95^{\circ} \mathrm{C}$ for $10 \mathrm{sec}, 60^{\circ} \mathrm{C}$ for $20 \mathrm{sec}$ and $70^{\circ} \mathrm{C}$ for $10 \mathrm{sec}$ using an ABI7500 real-time PCR system (Applied Biosystems). The relative miRNA expression level was calculated from three different experiments. The fold-change for miRNA relative to U6 was determined by the formula $2^{-\Delta \Delta \mathrm{Ct}}$.

Sphere colony formation assay. Gastric cancer cells were plated in each well of ultra-low-attachment 24-well plates (Corning Life Sciences, Corning, NY, USA) at low density (500 cells per each well) with $0.8 \%$ methyl cellulose (Sigma, USA) supplemented with $20 \mu \mathrm{l} / \mathrm{ml} \mathrm{B} 27$ supplement (Life Technologies), $20 \mathrm{ng} / \mathrm{ml}$ basic fibroblast growth factor (bFGF, Gibco), $10 \mathrm{ng} / \mathrm{ml}$ EGF (Gibco), LIF (Gibco), 1\% L-glutamine (Gibco) and $1 \%$ penicillin-streptomycin sulfate (Thermo Fisher Scientific). Every 3 days, each well was examined using light microscopy.

Invasion assay. Twenty-four-well, $8.0 \mu \mathrm{m}$ Transwells (BD Biosciences) were coated with diluted Matrigel (BD Biosciences) in PBS and dried for $1 \mathrm{~h}$. For the invasion assay, cells were suspended in medium without serum, and then $2 \times 10^{5}$ cells were seeded in the top chamber. Medium supplemented with $10 \%$ FBS was used as a chemoattractant in the bottom chamber. The cells were incubated for $8 \mathrm{~h}$ in a $37^{\circ} \mathrm{C}$ incubator supplemented with $5 \% \mathrm{CO}_{2}$. The non-invasive cells on the top chambers were removed with cotton swabs. The invaded cells on the lower membrane surface were fixed in $100 \%$ methanol for $15 \mathrm{~min}$ and washed in PBS three times, then stained with 4,6-diamidino-2-phenylindole (DAPI). Invaded cells were counted under a microscope. Three independent experiments were conducted and the data are presented as the mean \pm SEM.

miRNA inhibitor transfection. miR-196a-5p inhibitor and the negative control were obtained from Ribobio Co. FACS-sorted CD44(+) cells and CD44(-) cells were respectively seeded into 6 -well plates at a density of $1 \times 10^{5}$ cells/ well in antibiotic-free medium and incubated overnight. They were transfected with miRNA inhibitor or the negative control using Lipofectamine 2000 (Invitrogen) according to the manufacturer's instructions. The final concentration of miRNA inhibitor was $60 \mathrm{nM}$. The transfected cells were incubated for 
Table I. Primers used for the real-time PCR analysis.

\begin{tabular}{|c|c|c|}
\hline Gene & Direction & Primer sequences $\left(5^{\prime}-3^{\prime}\right)$ \\
\hline \multirow[t]{2}{*}{ CD44 } & $\mathrm{F}$ & GCTATTGAAAGCCTTGCAGAG \\
\hline & $\mathrm{R}$ & CGCAGATCGATTTGAATATAACC \\
\hline \multirow[t]{2}{*}{ Sox 2} & $\mathrm{~F}$ & AACCAAGACGCTCATGAAGAAG \\
\hline & $\mathrm{R}$ & CTGCGAGTAGGACATGCTGTAG \\
\hline \multirow[t]{2}{*}{ Oct 4} & $\mathrm{~F}$ & GACAACAATGAAAATCTTCAGGAGA \\
\hline & $\mathrm{R}$ & TTCTGGCGCCGGTTACAGAACCA \\
\hline \multirow[t]{2}{*}{ Nanog } & $\mathrm{F}$ & GTCCCAAAGGCAAACAACCC \\
\hline & $\mathrm{R}$ & GCTGGGTGGAAGAGAACACA \\
\hline \multirow[t]{2}{*}{ Smad4 } & $\mathrm{F}$ & GCTGCTGGAATTGGTGTTGATG \\
\hline & $\mathrm{R}$ & AGGTGTTTCTTTGATGCTCTGTCT \\
\hline \multirow[t]{2}{*}{ E-cadherin } & $\mathrm{F}$ & TGCTTGGTTCACCAGTGGAT \\
\hline & $\mathrm{R}$ & TTTTGTTGAGCAAGGCAACC \\
\hline \multirow[t]{2}{*}{$\mathrm{N}$-cadherin } & $\mathrm{F}$ & AACTCCAGGGGACCTTTTC \\
\hline & $\mathrm{R}$ & CAAATGAAACCGGGCTATC \\
\hline \multirow[t]{2}{*}{ Vimentin } & $\mathrm{F}$ & GAGAGGAAGCCGAAAACACC \\
\hline & $\mathrm{R}$ & GCTTGGAAACATCCACATCG \\
\hline \multirow[t]{2}{*}{ Slug } & $\mathrm{F}$ & CTTCCTGGTCAAGAAGCATT \\
\hline & $\mathrm{R}$ & TGAGGAGTATCCGGAAAGAG \\
\hline \multirow[t]{2}{*}{ Snail } & $\mathrm{F}$ & GGCCTTCAACTGCAAATACT \\
\hline & $\mathrm{R}$ & TTGACATCTGAGTGGGTCTG \\
\hline \multirow[t]{2}{*}{ GAPDH } & $\mathrm{F}$ & TGCACCACCAACTGCTTAGC \\
\hline & $\mathrm{R}$ & GGCATGGACTGTGGTCATGAG \\
\hline
\end{tabular}

$4 \mathrm{~h}$, and nomal media was added. The cells were harvested for the extraction of the RNA and protein after cultured for $72 \mathrm{~h}$.

Target prediction. The prediction of the target Smad4 3'-UTR as a miRNA binding target was performed using Targetscan (www.targetscan.org), microRNA (www.microrna.org) and PicTar (pictar.mdc-berlin.de). miRNAs that were positively predicted by all these programs were selected for this study.

Luciferase reporter assay. The 3'-UTR of Smad4 containing miR-196a-5p seed binding sites was cloned into the psiCHECK-2 vector to construct the wild-type (WT) vector (psicheck-SMAD4WT1 and psicheck-SMAD4-WT2). A mutant 3'-UTR of Smad4 was synthesized by PCR and cloned into the psiCHECK-2 vector to construct the mutation type (MuT) vector (psicheck-SMAD4MUT1 and psicheck-SMAD4-MUT2). SNU-5 sphere-like cells were seeded into $24-$ well plates $\left(1 \times 10^{5}\right.$ cells/well $)$ and transfected with psicheck-SMAD4-WT/MUT and miR-196a-5p mimics/ NC. Luciferase activities were measured by the dual-luciferase reporter assay system (Promega).

Plasmid construction and transfection. The coding domain sequence of Smad4 was synthesized and the DNA fragment was digested with $B a m \mathrm{HI}$ and EcoRI. The resulting fragment was subcloned into the BamHI and EcoRI sites of the pcDNA 3.1(+) vector (Invitrogen). The cell transfection was carried out with FuGENE HD reagent (Roche) according to the manufacturer's instructions.
Protein extraction and western blot analysis. Cultured cells were harvested after washing twice with ice-cold PBS. Protein was extracted from collected cells by Subcellular Protein Fractionation kit (Thermo Scientific Pierce). The protein concentration was detected using a BCA protein assay kit (Thermo Scientific Pierce). The same amount of protein was boiled at $95^{\circ} \mathrm{C}$ after adding isometric bromophenol blue (Amresco). Samples were loaded in 12\% SDS-PAGE gels for Sox2, Oct4, Nanog, Smad4, Vimentin, Slug, and Snail and in 6\% SDS-PAGE gels for E-cadherin and N-cadherin, and blotted onto PVDF membranes. After blocking, nitrocellulose blots were incubated for $1 \mathrm{~h}$ with primary antibodies diluted in TBS/ Tween-20 (0.075\%) containing 3\% Marvel. Mouse monoclonal antibody directed against SMAD4 (Santa Cruz Biotechnology, Inc., Santa Cruz, CA, USA) was diluted at 1:1,000. Rabbit monoclonal to CD44 (Abcam, USA) was diluted at 1:5,000. Rabbit polyclonal anti-Sox 2 (Cell Signaling Technology, USA) was used at 1:1,000 as was Oct4, Nanog, E-cadherin, $\mathrm{N}$-cadherin, Vimentin, Slug, and Snail. Peroxidase-conjugated affinipure goat anti-mouse and anti-rabbit antibodies were used as secondary antibodies correspondingly. After five washes in TBS/Tween-20, membranes with PBS were developed using the enhanced chemiluminescence system for the detection of antigen. Protein was visualized with ECL-chemiluminescent kit (Thermo Fisher Scientific).

Immunohistochemistery. Paraffin-embeded tissue samples were sectioned and stained for routine histology (Fuzhou Maixin Biotech Co., Ltd.). The sections were dewaxed in xylene and dehydrated in alcohol. Antigen retrieval was achieved by microwaving in citric acid buffer for $15 \mathrm{~min}$. After the peroxidase activity had been blocked with $3 \% \mathrm{H}_{2} \mathrm{O}_{2}$-methanol for $15 \mathrm{~min}$. The sections were incubated with $10 \%$ normal goat serum in PBS to block non-specific protein binding, followed by incubation with primary antibody against SMAD4 (1:300; Santa Cruz Biotechnology, Inc.) at $4^{\circ} \mathrm{C}$ overnight. After rinsing, the sections were incubated with biotinylated secondary antibody for $60 \mathrm{~min}$ at room temperature. SMAD4 expression was visualized by 3,3'-diaminobenzidine tetrahydrochloride (DAB) staining, followed by counterstaining with hematoxylin.

Statistical analysis. All experiments were repeated at least three times. All data were summarized and presented as means \pm SD. Statistical analyses were performed using SPSS 13.0 software (SPSS, Inc., Chicago, IL, USA). The differences between two groups were analyzed using a Student's t-test, and more than two groups were compared by a one-way analysis of variance (ANOVA). Data were considered significant at $\mathrm{P}<0.05$ or $\mathrm{P}<0.001$.

\section{Results}

Isolation and characteristics of human GCSCs. To isolate GCSCs, SNU-5 and BGC-823 cells were subjected to FACS sorting by anti-CD44 antibody. CD44(+) and CD44(-) cells were differentially isolated. After growing under serum-free conditions for 1-2 weeks, CD44(+) cells formed more and larger spheroid colonies than CD44(-) cells in both SNU-5 and BGC-823 cell lines (Fig. 1A). To determine stem cell characteristics of CD44(+) GCSCs, real-time PCR and western blot 

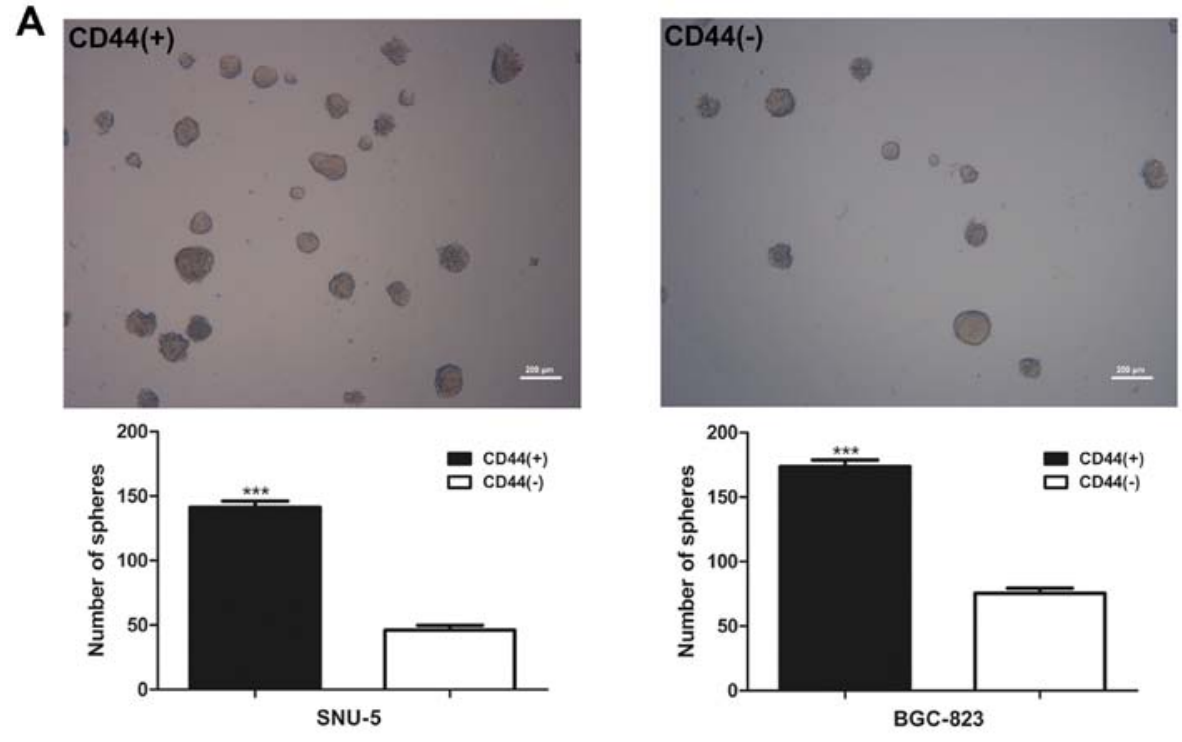

B

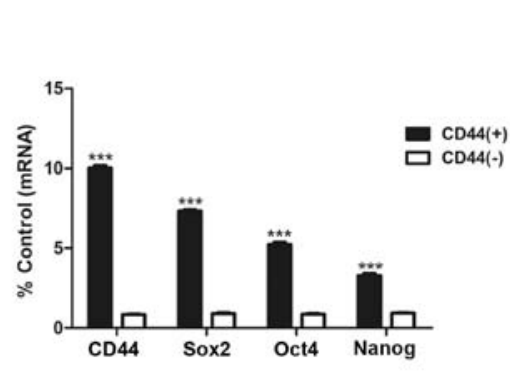

SNU-5

CD44

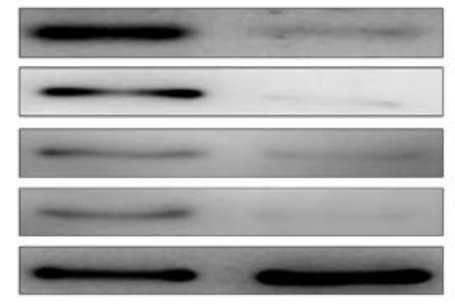

CD44

Sox2

Oct4

Nanog

GAPDH

BGC-823

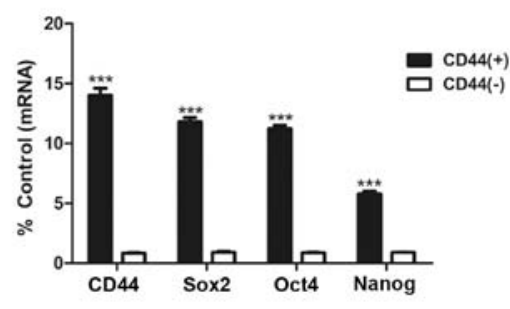

CD44

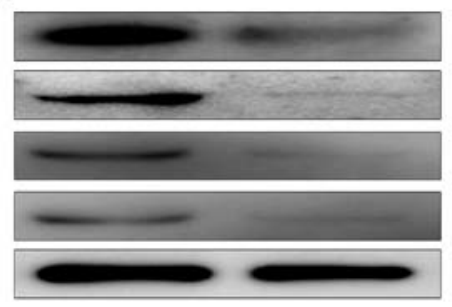

CD44

Sox2

Oct4

Nanog

GAPDH

Figure 1. CD44(+) cells show increased ability for sphere formation and upregulated cancer stem cell marker expression. (A) Sphere formation ability in CD44(+) and CD44(-) SNU-5 and BGC-823 cells were identified. The upper panel shows photographs of spheres in CD44(+) and CD44(-) BGC-823 cells. The graphs show the average number of spheres in triplicate. (B) mRNA expression of stem cell markers Sox2, Oct4, Nanog in CD44(+) and CD44(-) SNU-5 and BGC-823 cells was measured by real-time PCR (left panel). Protein expression of these markers was analyzed by western blotting (right panel).

analysis were used to evaluate mRNA and protein expression of stem cell markers Sox2, Oct4, Nanog in CD44(+) and CD44(-) cells. The results indicated that the mRNA and protein expression of Sox 2, Oct4 and Nanog were both significantly higher in CD44(+) cells than CD44(-) cells in both SNU-5 and BGC-823 cell lines (Fig. 1B).

CD44(+) cells show an increased invasion capacity and EMT characteristics compared with CD44(-) cells. CSCs have higher invasion and migration capacity, which is considered as the crucial characteristic to facilitate tumor metastasis and growth. Matrigel invasion assay was used to compare the invasion abilities of CD44(+) and CD44(-) cells. CD44(+) cells possess higher invasion capacity than CD44(-) cells (Fig. 2A).

EMT is a widespread developmental program that regulates cell migration in many tissues and organs. Growing evidence reveals that EMT contributes to the invasion and metastasis of CSCs. We then detected several well-known EMT markers at both mRNA and protein level. The epithelial marker E-cadherin was downregulated in CD44(+) cells. On the other hand, the expression of $\mathrm{N}$-cadherin, vimentin, slug and snail were higher in CD44(+) SNU-5 and BGC-823 cells (Fig. 2B).

miR-196a-5p is upregulated in CD44(+) cells in microarray analysis. Microarry analysis revealed a series of miRNAs upregulated in CD44(+) cells compared with CD44(-) cells (Fig. 3A). Real-time PCR validated that the expression of miR-196a-5p, miR-122-5p, miR-155-5p, miR-30a-5p, miR-30b-5p and miR-30c-5p in CD44(-) cells was less than that in CD44(+) cells (Fig. 3B).

In our pre-screening studies, miR-196a-5p showed the most significant biological functions on GCSCs among the 

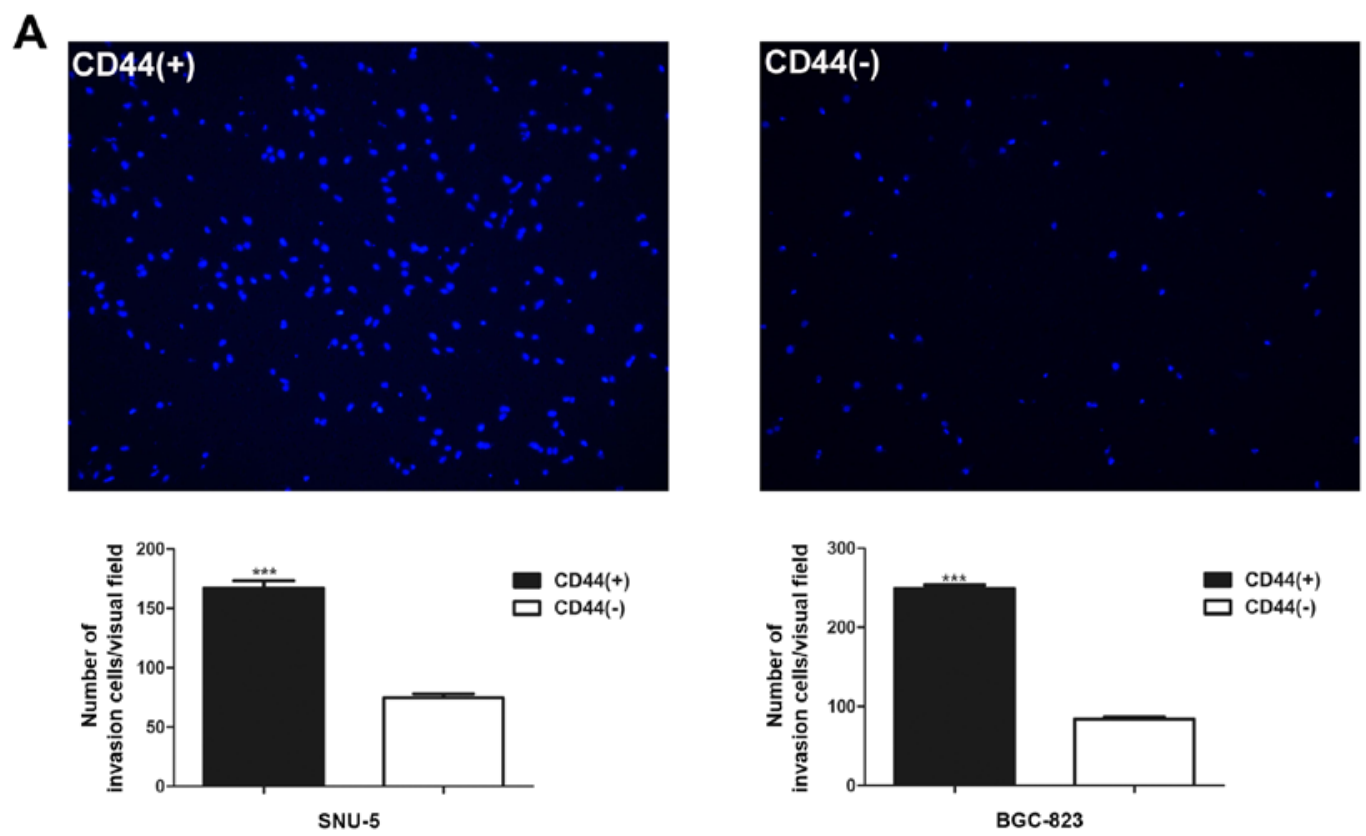

B
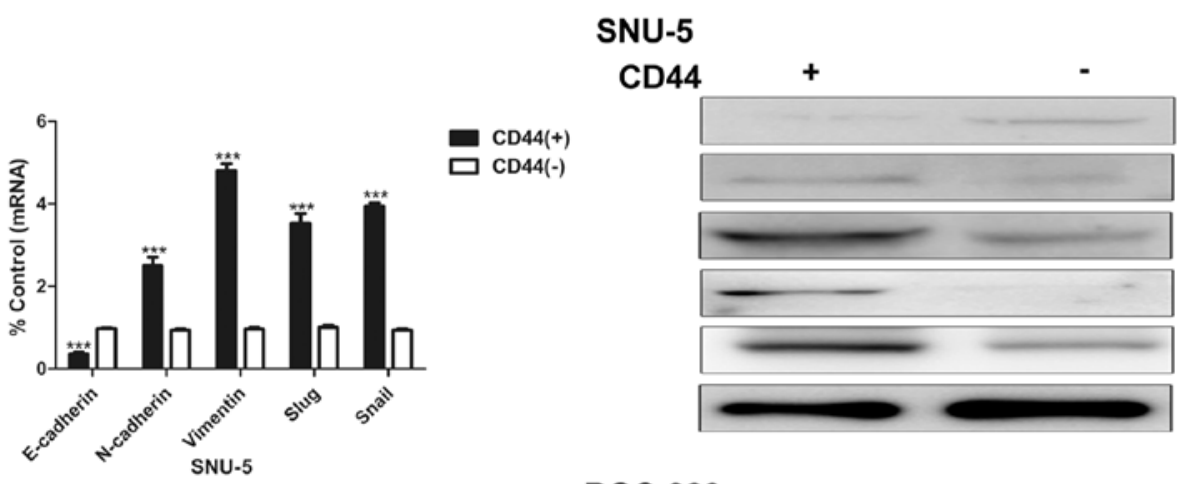

\section{E-cadherin}

$\mathrm{N}$-cadherin

Vimentin

Slug

Snail

GAPDH

\section{BGC-823}
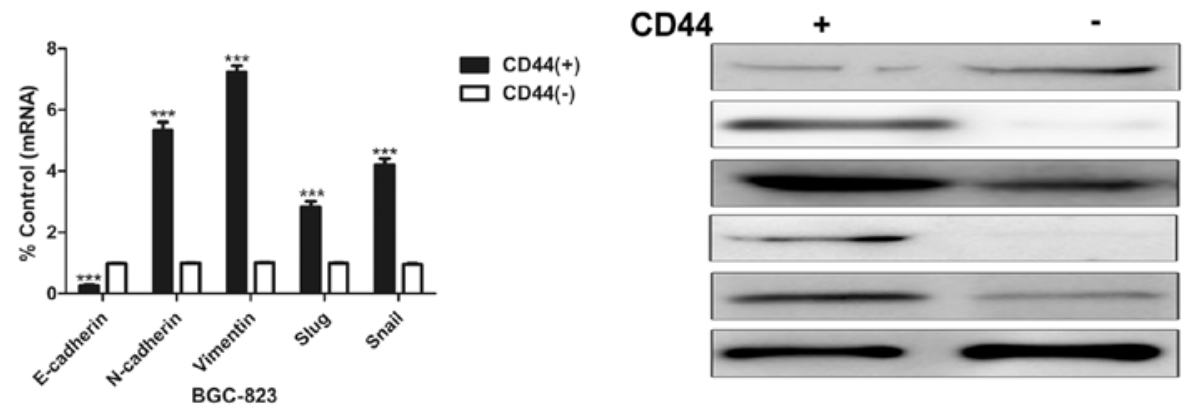

\section{E-cadherin}

$\mathrm{N}$-cadherin

Vimentin

Slug

Snail

GAPDH

Figure 2. CD44(+) cells show mesenchymal characteristics compared with CD44(-) cells. (A) Cell invasion capacity was identified by Matrigel invasion assay. The upper panel shows photographs of invasion cells in CD44(+) and CD44(-) BGC-823 cells. The graphs show the average number of invasive cells in both SNU-5 and BGC-823 cells in triplicate. (B) The expression level of EMT markers was measured by real-time PCR (left panel) and western blotting (right panel). The expression of N-cadherin, vimentin, slug and snail were higher in CD44(+) than SNU-5 and BGC-823 cells, but the epithelial marker E-cadherin was downregulated in CD44(+) cells.

upregulated miRNAs identified aforementioned. Additionally, there is still no relevant research on miR-196a-5p in the field of GCSCs. This prompted us to carry out further study on the regulatory mechanism of miR-196a-5p on cancer stem-like cell characteristics.

miR-196a-5p regulates the self-renewal capacity and invasion ability in CD44(+) cells. To evaluate the effect of miR-196a-5p on the self-renewal capacity, we initially carried out sphere colony formation assay of CD44(+) and CD44(-) cells transfected with miR-196a-5p inhibitor. As shown in Fig. 4A, miR-196a-5p knockdown significantly decreased the sphere colony forming capacity of CD44(+) cells (Fig. 4A). The expression of CD44 and cancer stem cell markers at mRNA and protein levels were determined by real-time PCR and western blot analysis respectively. Compared with CD44(+) cells transfected with the negative control, the expression of these genes were relatively downregulated in 
A

\begin{tabular}{lc}
\multicolumn{1}{c}{ miRNAs } & Fold change \\
\hline hsa-miR-3185 & 3.66 \\
hsa-miR-196a-5p & 3.34 \\
hsa-miR-139-5p & 2.99 \\
hsa-miR-122-5p & 2.96 \\
hsa-miR-3911 & 2.65 \\
hsa-miR-30a-3p & 2.53 \\
hsa-miR-181d-5p & 2.52 \\
hsa-miR-30c-5p & 2.38 \\
hsa-miR-424-3p & 2.36 \\
hsa-miR-30b-5p & 2.29 \\
hsa-miR-4286 & 2.22 \\
hsa-miR-4649-3p & 2.20 \\
hsa-miR-125a-5p & 2.17 \\
hsa-miR-15b-5p & 2.16 \\
hsa-miR-151b & 2.11 \\
hsa-miR-155-5p & 2.09 \\
hsa-miR-30a-5p & 2.03 \\
\hline
\end{tabular}

B

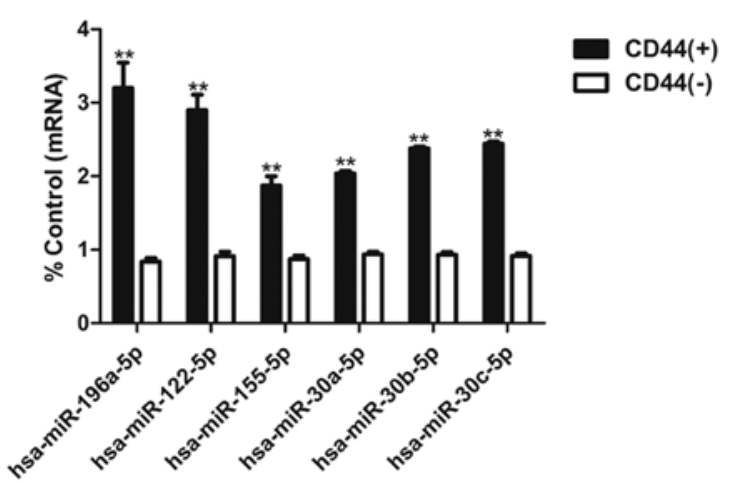

Figure 3. miR-196a-5p is upregulated in CD44(+) cells. (A) miRNAs upregulated in CD44(+) cells are listed in the table (fold change $>2$ ). (B) Expression of miR-196a-5p was confirmed using real-time PCR.

the CD44(+) cells transfected with miR-196a-5p inhibitor to similar levels in CD44(-) cells (Fig. 4B). These data indicate that the miR-196a-5p expression may promote the self-renewal ability of GCSCs.

Next, we investigated the role of miR-196a-5p in regulating invasion ability of GCSCs. After $48 \mathrm{~h}$, the number of invading cells in each group was counted. The results illustrate that the number of invasive CD44(+) cells markedly decreased after miR-196a-5p was inhibited (Fig. 5A). Moreover, the effects of miR-196a-5p on EMT were studied. As measured by real-time PCR and western blotting, E-cadherin was upregulated, whereas $\mathrm{N}$-cadherin, vimentin, slug and snail were downregulated in miR-196a-5p inhibitor-transfected CD44(+) cells (Fig. 5B). Collectively, these data demonstrate that miR-196a-5p promotes EMT and invasion of GCSCs.

Smad4 is a direct and specific target of miR-196a-5p in GCSCs. To determine how miR-196a-5p may regulate EMT and invasion, we applied three bioinformatic algorithms (TargetScan, PicTar and miRanda) to search for potential targets of miR-196a-5p. Based on the bioinformatics prediction, there are two conserved binding sites, 867-888 and 5304-5324, in the 3'-UTR region of the Smad4 mRNA targeted by miR-196a-5p (Fig. 6A). To validate the results of computational analysis, we used real-time PCR and western blotting to compare Smad4 expression in CD44(+) and CD44(-) cells isolated from two human gastric cancer cell lines which were transfected with or without miR-196a-5p inhibitor. As shown in Fig. 6B, Smad4
Table II. Relationship between Smad4 expression and pathological parameters in 95 gastric cancer patients.

\begin{tabular}{lcccc}
\hline & & \multicolumn{2}{c}{ Smad4 expression } & \\
\cline { 3 - 4 } Characteristics & $\mathrm{n}$ & Negative & Positive & P-value \\
\hline Age (years) & & & & \\
$\quad<60$ & 26 & 23 & 3 & 0.206 \\
$\geq 60$ & 69 & 53 & 16 & \\
Gender & & & & \\
Male & 70 & 54 & 16 & 0.244 \\
Female & 25 & 22 & 2 & \\
Differentiation & & & & \\
PD & 80 & 69 & 11 & $0.001^{\mathrm{a}}$ \\
MD & 13 & 7 & 6 & \\
WD & 2 & 0 & 2 & \\
TNM stage & & & & \\
I+II & 27 & 16 & 11 & $0.001^{\mathrm{a}}$ \\
III+IV & 68 & 60 & 8 & \\
Depth of invasion & & & & \\
T1 + T2 & 31 & 21 & 10 & $0.038^{\mathrm{a}}$ \\
T3 + T4 & 64 & 55 & 9 & \\
\hline & & & & \\
\hline
\end{tabular}

$\mathrm{PD}$, poorly differentiated; MD, moderately differentiated; WD, well differen-

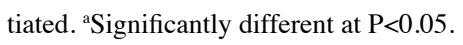

mRNA and protein expression were significantly increased after inhibition of miR-196a-5p (Fig. 6B).

To obtain further direct evidence that miR-196a-5p alters Smad4 expression, we performed luciferasre reporter assays. Remarkably, luciferase analysis showed that miR-196a-5p mimics repressed the activities of psicheck-SMAD4-WT1 and psicheck-SMAD4-WT2. In contrast, psicheck-SMAD4-MUT, in which the binding sites of miR-196a-5p are mutated, showed higher luciferase activities than psicheck-SMAD4-WT. Additionally, transfection of miR-196a-5p mimics had no suppression or activation of psicheck-SMAD4-MUT1 and psicheck-SMAD4-MUT2 (Fig. 6C). Thus, the expression of miR-196a-5p is inversely correlated with Smad4, indicating that Smad4 may be a direct and specific target of miR-196a-5p for regulatory functions in GCSCs.

Overexpression of Smad4 decreases GCSCs invasion ability. To further characterize the function of Smad4 in GCSCs, we examined the effects of Smad4 overexpression on the invasion capacity of GCSCs. Overexpression of Smad4 markedly decreased the invasion ability of CD44(+) GCSCs (Fig. 7A). After Smad4 overexpression in CD44(+) SNU-5 cells, the expression of $\mathrm{N}$-cadherin, vimentin, slug and snail were downregulated, whereas E-cadherin was upregulated. Similar results were observed in BGC-823 cells (Fig. 7B).

Correlation between the expression of Smad4 and pathological parameters in gastric cancer patients. To investigate the clinical significance of Smad4 in gastric cancer development, the expression of Smad4 was analyzed 

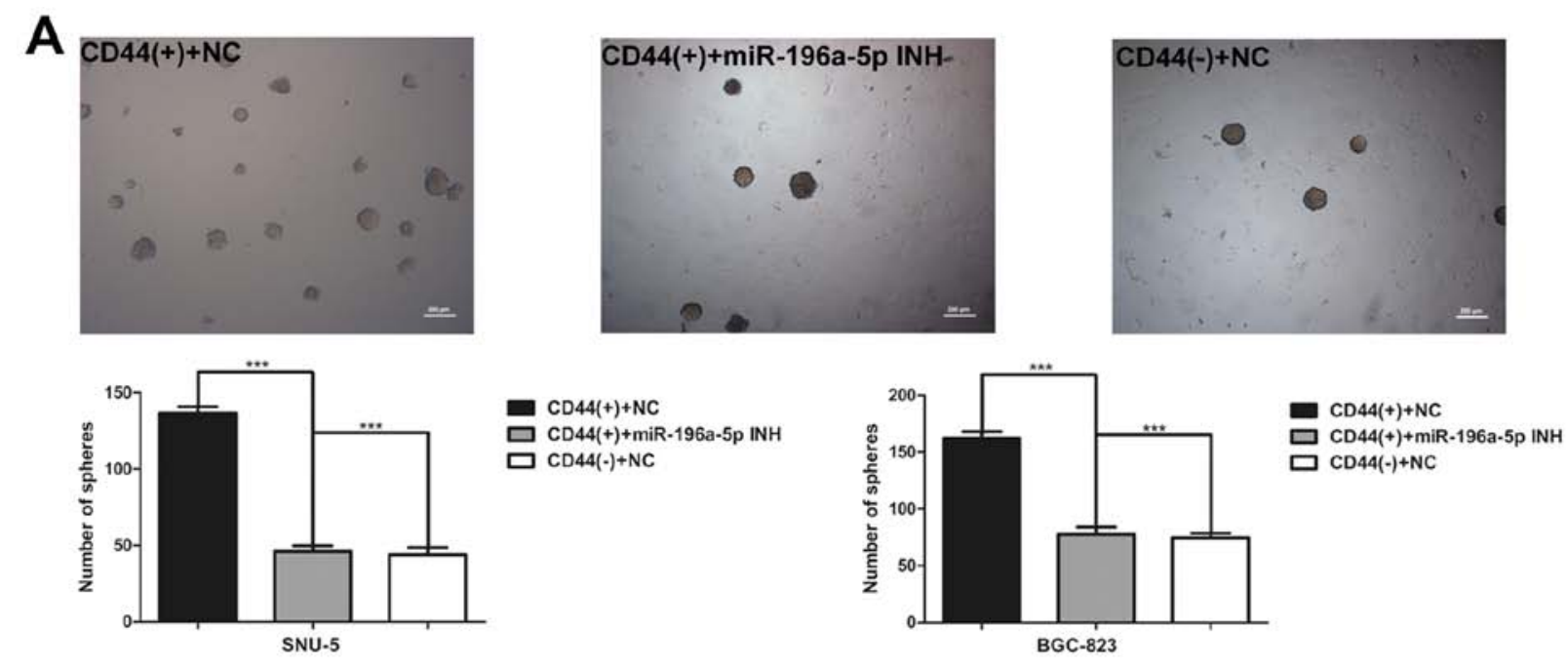

B

SNU-5
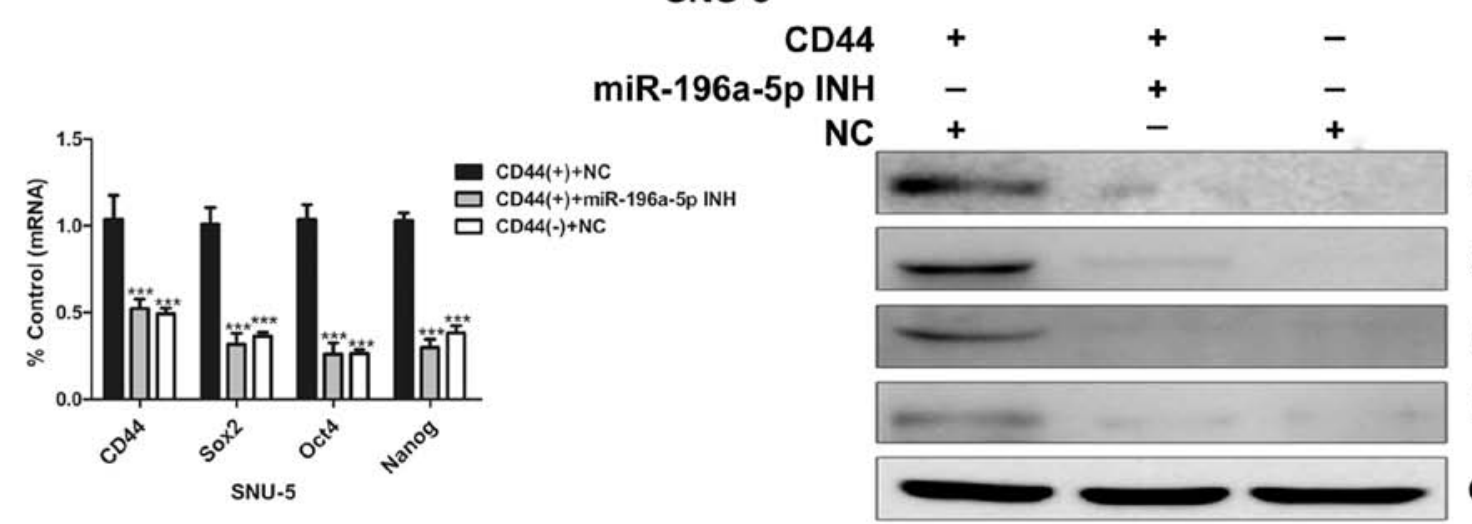

CD44

Sox2

Oct4

Nanog

GAPDH

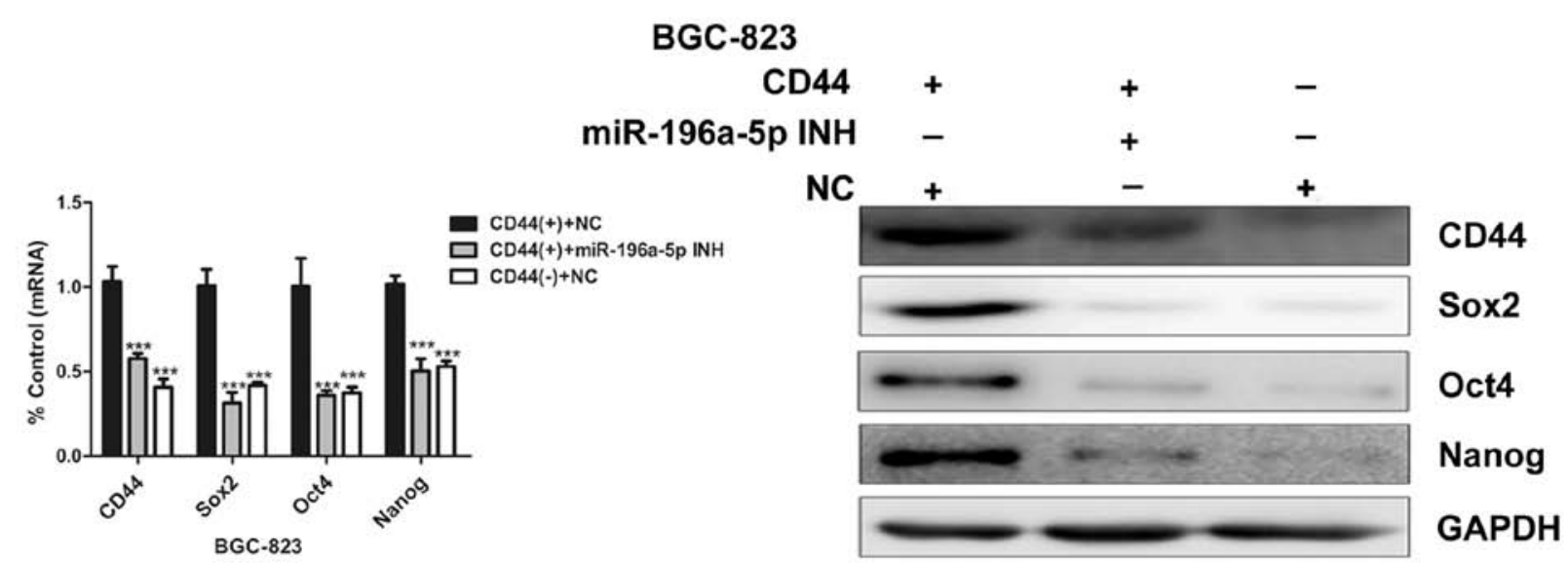

Figure 4. Inhibition of miR-196a-5p expression suppresses the self-renewal capacity in CD44(+) cells. (A) Sphere colony formation in CD44(+), CD44(-) cells transfected with negative control and CD44(+) cells transfected with miR-196a-5p inhibitor in SNU-5 and BGC-823 cells were identified in a low-attachment plate with serum-free media. The photograghs show colony formation in BGC-823 cells (upper panel). The graphs show the average number of spheres in triplicate (lower panel). (B) The cancer stemness gene expression was detected by real-time PCR and western blotting. NC, negative control; miR-196a-5p INH, miR-196a-5p inhibitor.

by immunohistochemistry (IHC) staining in 95 gastric cancer cases and paired adjacent non-tumorous tissues. IHC staining confirmed that the downregulation of Smad4 in gastric cancer tissues compared with adjacent non-tumorous tissues (Fig. 8). Next, we detected the relationship between pathological characteristics and Smad4 expression levels in gastric cancer patients. No significant association between Smad4 expression levels and the patient age, and sex was detected in 95 gastric cancer cases (Table II). However, the levels of Smad4 were significantly correlated with differentiation state, TNM stage and depth of invasion (Table II). Importantly, Smad4 expression was negatively correlated with differentiation of tumors. 

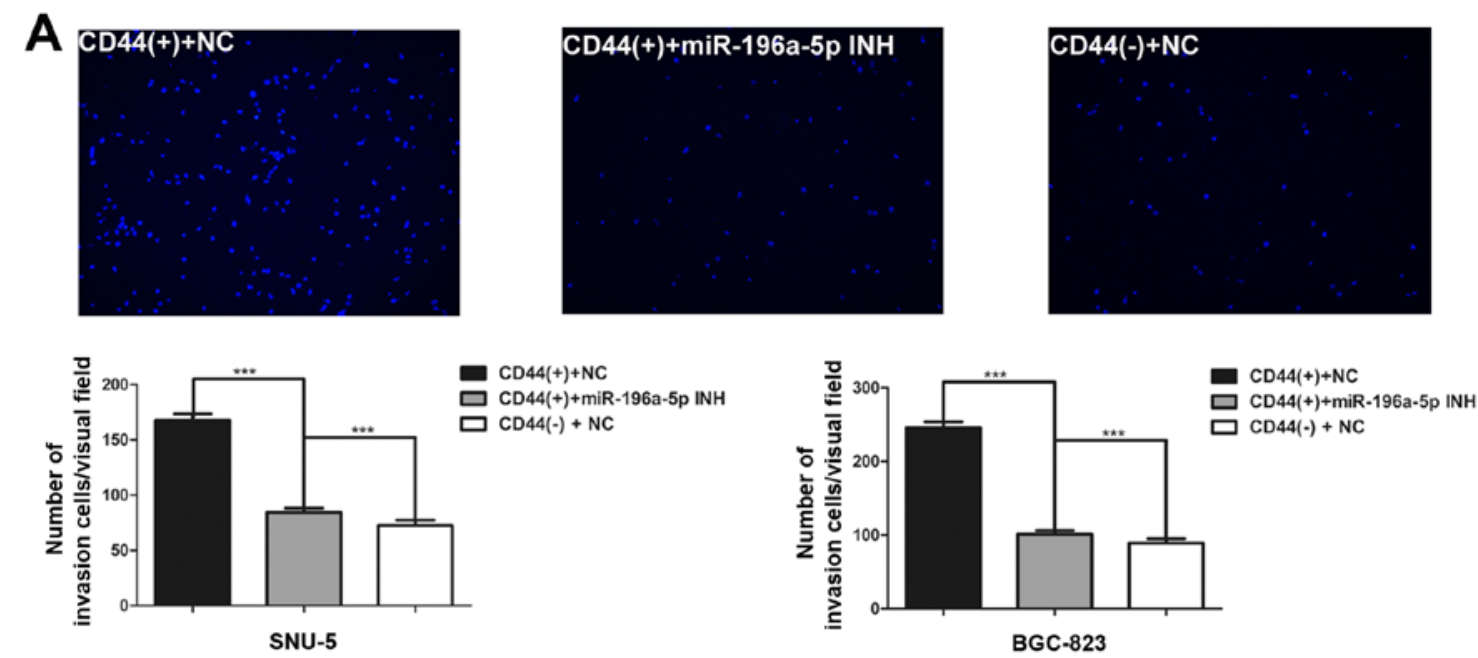

B
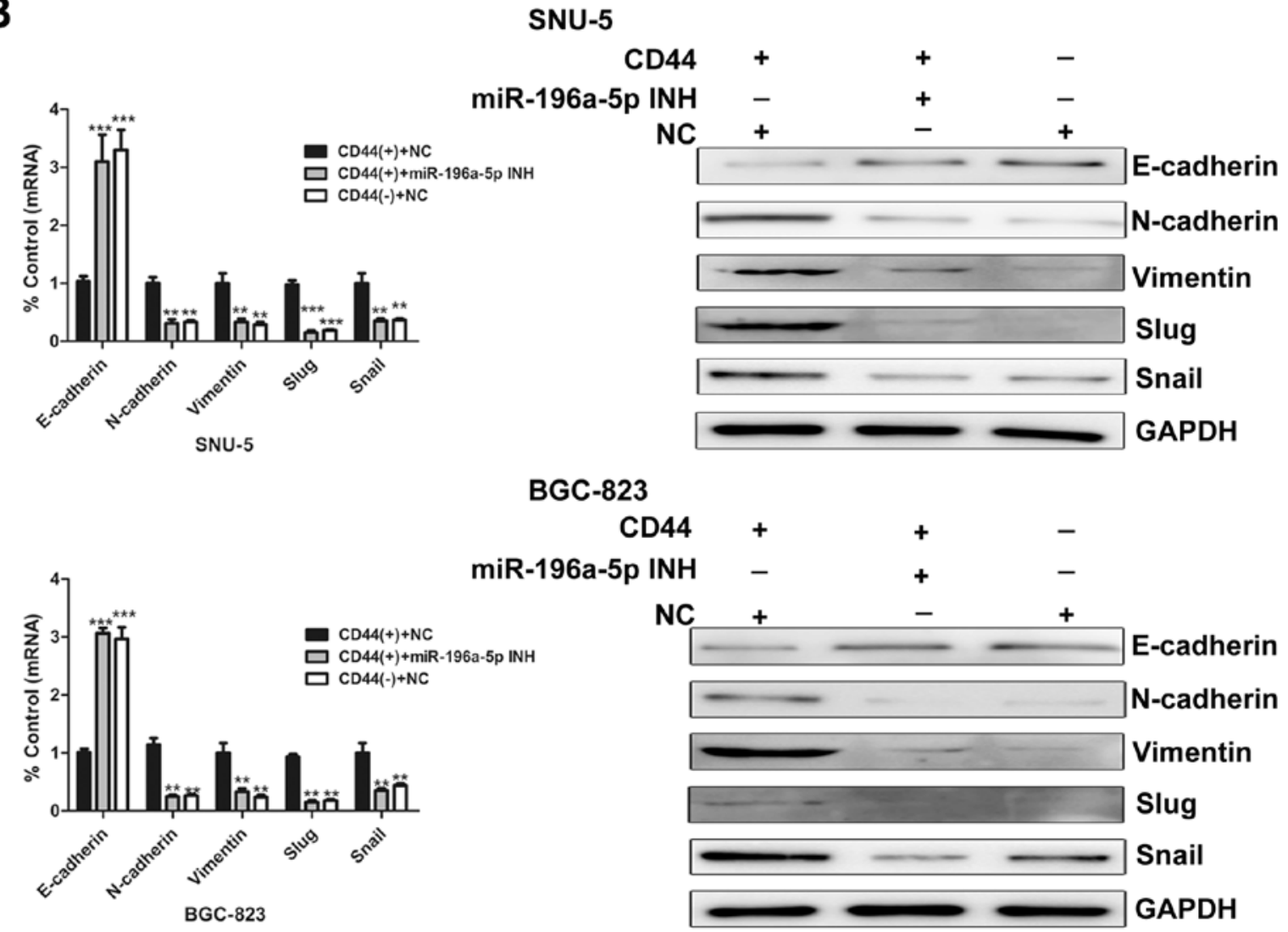

Figure 5. Inhibition of miR-196a-5p expression suppresses the invasion ability in CD44(+) cells. (A) The invasion ability was identified using Matrigel-coated invasion assay. Invaded cells were counted and converted to the graph. (B) Real-time PCR and western blotting were used to investigate EMT marker expression in the above-described groups. NC, negative control; miR-196a-5p INH, miR-196a-5p inhibitor.

\section{Discussion}

RNA is probably the first macromolecule evolved in life and may play a crucial role in regulating the cell functions. In addition to the well recognized members of tRNA, mRNA, and rRNA related to the genetic central dogma, several types of small RNAs, such as miRNAs, have been recently identified responsible for the tight regulation of gene expression and cellular function. In the present study, we have associated the relationship between miR-196a-5p and gastric cancer, and further narrowed the possible target Smad4 in affecting the characteristics of gastric cancer stem cells.

There is increasing evidence that tumors are composed of phenotypically and functionally diverse populations of neoplastic cells. Furthermore, the subpopulations with stem cell properties, the CSCs are closely related to cancer development, metastasis and resistance to therapy. CSCs are characteristic of self-renewal and differentiation capacity, high 
A

miR-196a-5p 3'- GGUUGUUGUACUUUGAUGGAG -
SMAD4 3'-UTR (867-888)....AAAAGGCAGCG TCACT CTACCTA...

SMAD4 3'-UTR-mut ...AAAAGCAGCG TCACT GATGGAA...

Site-B

miR-196a-5p

SMAD4 3'-UTR (5304-5324) CTAAGTGAC CT - TGGCT II I I I

SMAD4 3'-UTR-mut

CTAAGTGAC CT - TGGGATGGAT

B

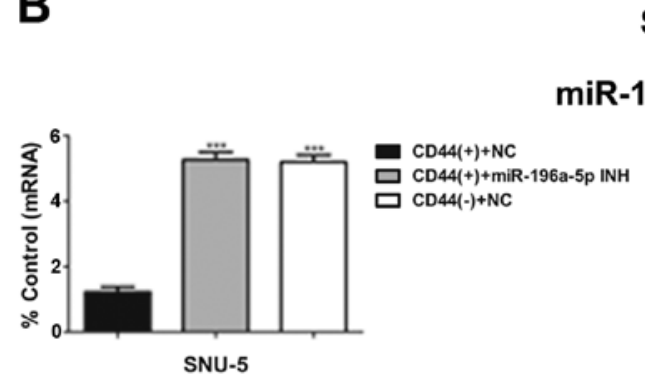

SNU-5

CD44

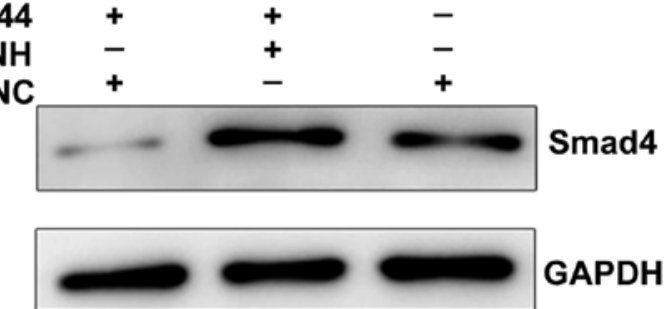

BGC-823

CD44

miR-196a-5p INH

NC

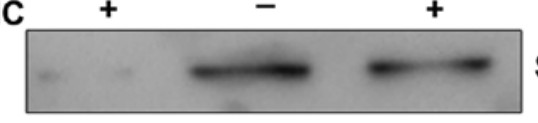

Smad4

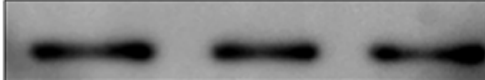

GAPDH

C

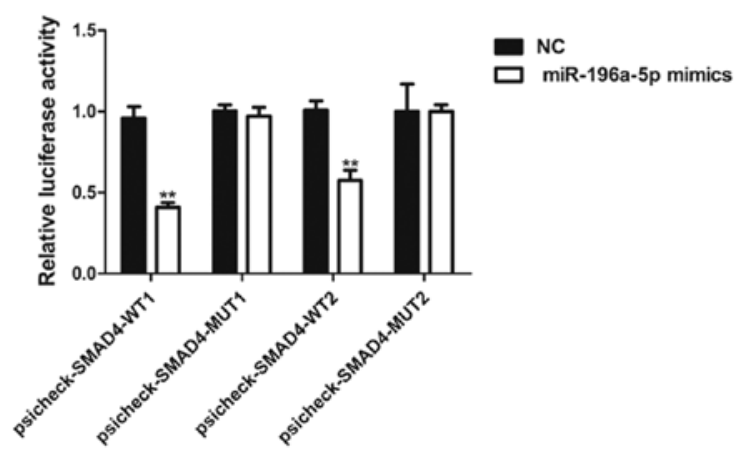

Figure 6. miR-196a-5p targets Smad4 by binding to its 3'-UTR. (A) Putative miR-196a-5p binding sequences in the 3'-UTR of Smad4 mRNA. (B) The expression of Smad4 was examined by real-time PCR and western blotting after transfection of miR-196a-5p inhibitor in SNU-5 and BGC-823 cells. (C) SNU-5 cells were cotransfected with miR-196a-5p mimics and luciferase reporters containing either the predicted miRNA target site or its corresponding mutant form.

tumorigenesis and invasiveness, resistance to chemotherapy and radiation, genetic and epigenetic changes. Numerous therapeutic approaches for eradicating CSCs have been proposed. Generally, the core idea can be envisaged: eliminating the CSCs themselves by either killing or differentiating them, and disruption of niche signaling. According to ClincalTrials.gov, some anti-CSCs compounds have been already completed different phases of testing and successfully entered human clinic trials. Therefore, therapeutic approaches targeting CSCs bring new hope for future antitumor treatment. As the crucial regulator of gene expression in cell cycle, miRNAs act as oncogenes or tumor suppressor genes in cancer development. Additionally, aberrantly expressed miRNAs play a major role in the biological properties of CSCs. Therefore, miRNAs have been identified as the attractive target for anti-CSC therapies.

In this study, several stem cell surface markers were tested in order to select the appropriate marker for GCSCs isolation, such as CD44, EpCAM and CD133. More than 99\% of SNU-5 

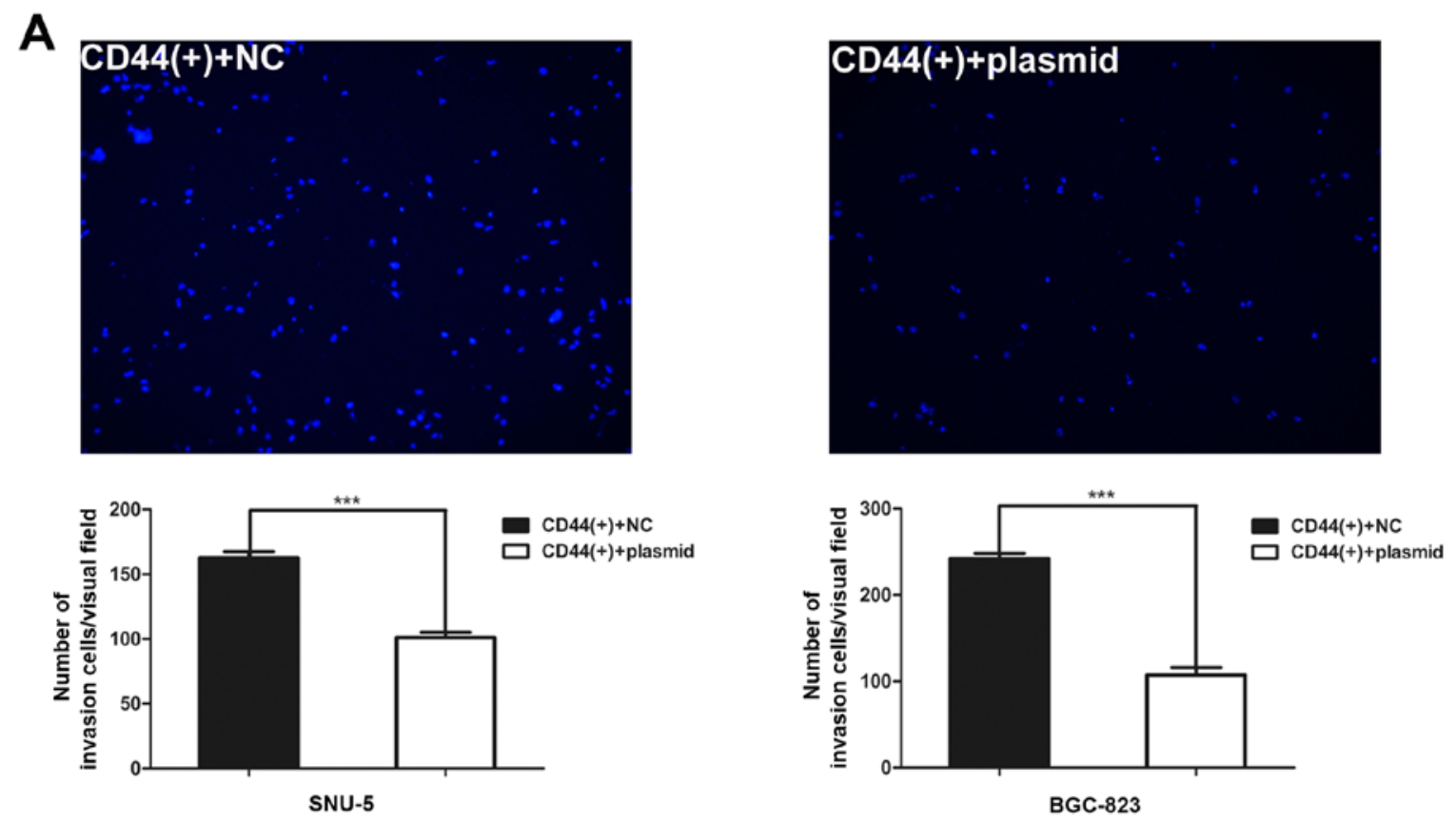

B
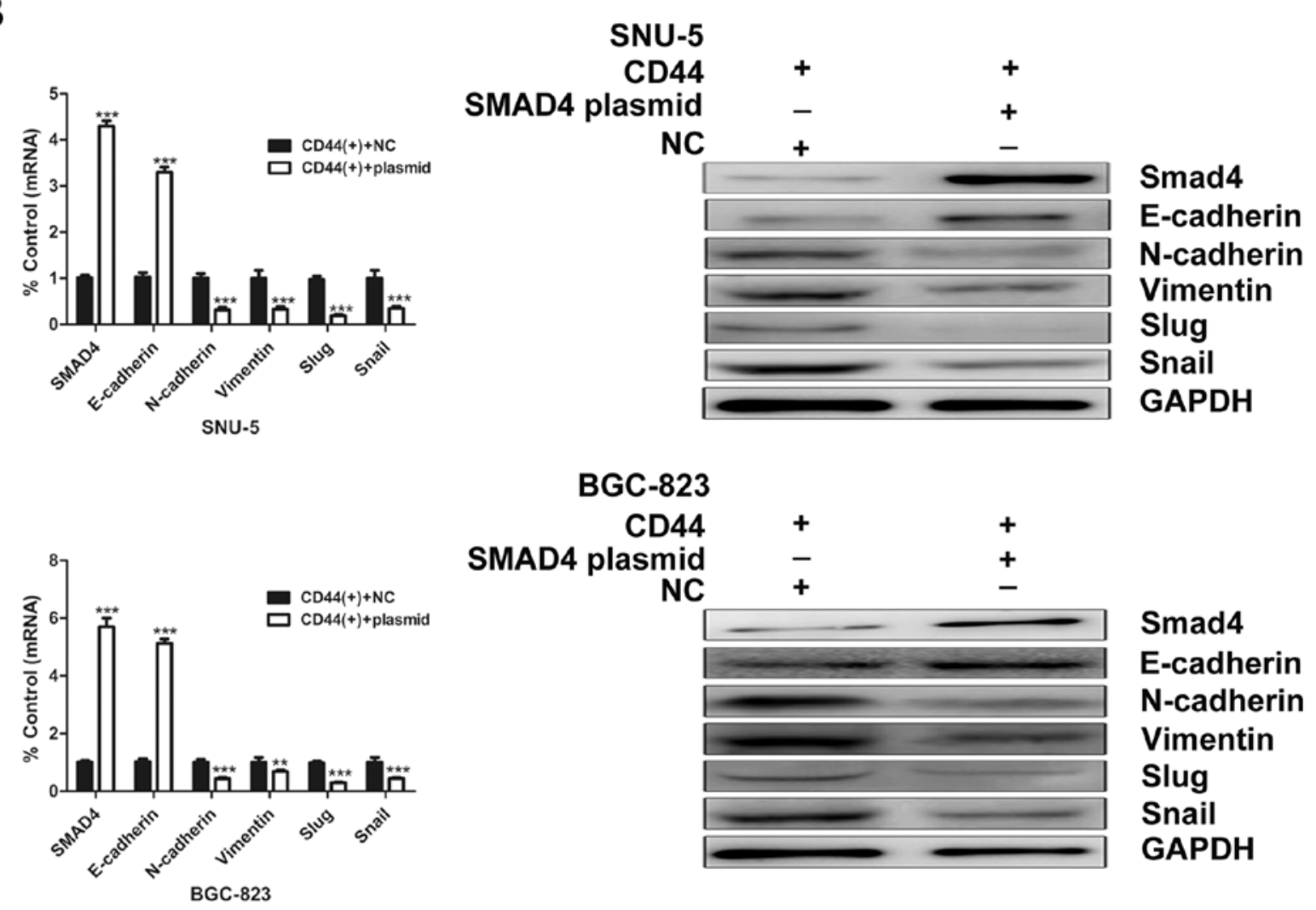

Figure 7. Overexpression of Smad4 decreased GCSC invasion ability. (A) The invasion ability was detected in CD44(+) after transfection of Smad4 plasmid or negative control. (B) The expression level of EMT markers were measured by both real-time PCR and western blotting in the above groups.

and BGC-823 cell populations expressed the above markers except CD44 (data not shown). Similar results have been reported previously (28-30). Based on our previous studies, CD44 was successfully selected as a surrogate marker of GCSCs. Compared with CD44(-) cells, FACS-sorted CD44(+) cells showed many cancer stem-like cell charateristics. First, the self-renewal capacity of cells was examined by sphere formation ability. CD44(+) cells form more sphere colonies than CD44(-) cells in SNU-5 and BGC-823 cell lines. The expression of stem cell markers was upregulated at the mRNA and protein levels. Second, CD44(+) cells possess stronger invasive ability than CD44(-) cells. In terms of molecular 
A Adjacent non-tumorous tissues

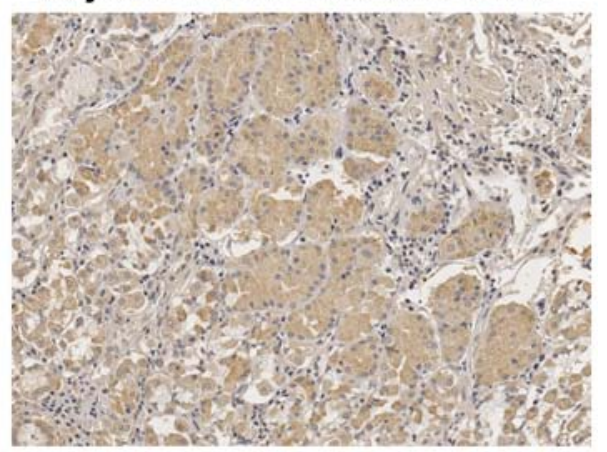

B Gastric cancer tissues

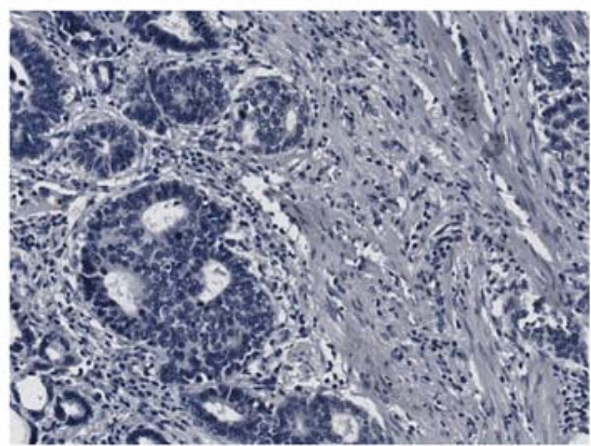

Figure 8. Representative images of Smad4 immunohistochemistry (IHC) staining in gastric cancer tissues and adjacent non-tumorous tissues. (A) The expression of Smad4 is upregulated in adjacent non-tumorous tissues. (B) IHC staining shows that Smad4 expression was downregulated in gastric cancer tissues.

expression and phenotype of EMT properties, CD44(+) cells manifested a biological transformation toward mesenchymal cell types. However, CD44(+) alone cannot be used as an exclusive marker of CSCs since CD44(-) can also show sphere formation in culture and develop cancer in animals. Our miRNA microarray data documented that miR-196a-5p was significantly upregulated in CD44(+) cells compared with CD44(-) cells. Although there were other miRNAs overexpressed in CD44(+) cells, miR-196a-5p was firstly selected to further study according to the following two facets. First, miR-196a-5p is a newly reported miRNA relevant to multiple cancers, but there is still no report on its role in CSCs. Second, miR-196a-5p had the most significant effects on cancer stemlike cell charateristics in our pre-screening studies.

The present study provided evidence indicating that the newly found target gene of miR-196a-5p is Smad4, which functions as $\mathrm{Co}-\mathrm{Smad}$ in $\mathrm{TGF}-\beta / \mathrm{Smad}$ signaling pathway. When TGF- $\beta 1$ binds to its receptor, $\mathrm{Smad} 2 / 3$ is phosphorylated and binds with Smad4 to form multimers and translocate to the nucleus to drive the transcriptional regulation of several target genes (31-34). Emerging evidence suggests the TGF- $\beta$ signaling pathway has a major role in EMT resulting in tumor metastasis and recurrence. Our data also showed that miR-196a-5p regulated EMT through the TGF- $\beta /$ Smad signaling pathway. Interestingly, the stimulation of epithelial-mesenchymal transition (EMT) by miR-196a-5p in cancer stem-like cells was abolished by overexpression of Smad4. Collectively, the expression of Smad4 in gastric cancer tissues was correlated with differentiation state of tumors, TNM stage and depth of invasion.

Based on the above-mentioned data, it is strongly suggested that miR-196a-5p markedly modulates gastric cancer stem cell characteristics by targeting Smad4. Hence, it is necessary and valuable to transform this observation to clinical therapeutics. There are important aspects for our future clinical studies. First, we will measure the miR-196a-5p expression level in gastric cancer patients and analyze the relationship between the miR-196a-5p expression level and clinical characteristics, particularly metastasis, invasion of gastric cancer. Additionally, the aforementioned studies can also be observed in other types of cancer to confirm the general role of miR-196a-5p in affecting the phenotypes of cancers. Lastly, we will strive to develop miR-196a-5pbased therapeutic agents by various technologies including nanocapsules and nanocarriers, liposomes and PEGylated vesicles.

On the basis of the current state of knowledge, it is reasonable to suggest that miRNAs-based approaches may represent one of the novel and promising therapeutics. Currently, several therapeutic strategies targeting miRNAs have been used in the clinic. Growing evidence indicates that miRNAs regulate cancer development in a traditional manner by regulating signaling pathways and factors. On the other hand, a non-conventional mechanism of cancer regulation by stem cell reprogramming via a regulatory network consisting of miRNAs that could modulate stem cell properties of CSCs.

\section{Acknowledgements}

This study was supported by grants from The National High Technology Research and Development Program of China (863 Program) (2014AA020537), National Natural Science Foundation of China (31371445).

\section{References}

1. Torre LA, Bray F, Siegel RL, Ferlay J, Lortet-Tieulent J and Jemal A: Global cancer statistics, 2012. CA Cancer J Clin 65: 87-108, 2015.

2. Chen W, Zheng R, Zhang S, Zhang S, Zhao P, Li G, Wu L and He J: Report of incidence and mortality in China cancer registries, 2009. Chin J Cancer Res 25: 10-21, 2013.

3. Kim TH and Shivdasani RA: Stomach development, stem cells and disease. Development 143: 554-565, 2016.

4. Jordan CT, Guzman ML and Noble M: Cancer stem cells. N Engl J Med 355: 1253-1261, 2006.

5. Zhang X, Hua R, Wang X, Huang M, Gan L, Wu Z, Zhang J, Wang H, Cheng Y, Li J, et al: Identification of stem-like cells and clinical significance of candidate stem cell markers in gastric cancer. Oncotarget 7: 9815-9831, 2016.

6. Alison MR, Lin WR, Lim SM and Nicholson LJ: Cancer stem cells: In the line of fire. Cancer Treat Rev 38: 589-598, 2012.

7. Liu TJ, Sun BC, Zhao XL, Zhao XM, Sun T, Gu Q, Yao Z, Dong XY, Zhao N and Liu N: CD133 ${ }^{+}$cells with cancer stem cell characteristics associates with vasculogenic mimicry in triplenegative breast cancer. Oncogene 32: 544-553, 2013.

8. Sakakini N, Turchi L, Bergon A, Holota H, Rekima S, Lopez F, Paquis P, Almairac F, Fontaine D, Baeza-Kallee N, et al: A positive feed-forward loop associating EGR1 and PDGFA promotes proliferation and self-renewal in glioblastoma stem cells. J Biol Chem 291: 10684-10699, 2016.

9. Nataraj SM, Prema CL, Vimalambike MG, Shivalingaiah SC, Sundaram S, Kumar AP, Math AK and Prashant A: Major protein of carcinoembryonic antigen gene family - CD66c, a novel marker in colon carcinoma. J Clin Diagn Res 10: XC01-XC04, 2016. 
10. Liu J, Ma L, Xu J, Liu C, Zhang J, Liu J, Chen R and Zhou Y: Spheroid body-forming cells in the human gastric cancer cell line MKN-45 possess cancer stem cell properties. Int J Oncol 42: 453-459, 2013.

11. Takebe N, Harris PJ, Warren RQ and Ivy SP: Targeting cancer stem cells by inhibiting Wnt, Notch, and Hedgehog pathways. Nat Rev Clin Oncol 8: 97-106, 2011.

12. Sounni NE and Noel A: Targeting the tumor microenvironment for cancer therapy. Clin Chem 59: 85-93, 2013.

13. Lim YC, Kang HJ, Kim YS and Choi EC: All-trans-retinoic acid inhibits growth of head and neck cancer stem cells by suppression of Wnt/ $\beta$-catenin pathway. Eur J Cancer 48: 3310-3318, 2012.

14. Li Y, Zhang T, Korkaya H, Liu S, Lee HF, Newman B, Yu Y, Clouthier SG, Schwartz SJ, Wicha MS and Sun D: Sulforaphane, a dietary component of broccoli/broccoli sprouts, inhibits breast cancer stem cells. Clin Cancer Res 16: 2580-2590, 2010.

15. Yang T and Rycaj K: Targeted therapy against cancer stem cells. Oncol Lett 10: 27-33, 2015

16. Leon G, MacDonagh L, Finn SP, Cuffe S and Barr MP: Cancer stem cells in drug resistant lung cancer: Targeting cell surface markers and signaling pathways. Pharmacol Ther 158: 71-90, 2016.

17. Lau WM, Teng E, Chong HS, Lopez KA, Tay AY, Salto-Tellez M, Shabbir A, So JB and Chan SL: CD44v8-10 is a cancer-specific marker for gastric cancer stem cells. Cancer Res 74: 2630-2641, 2014.

18. Mansour SF and Atwa MM: Clinicopathological significance of CD133 and ALDH1 cancer stem cell marker expression in invasive ductal breast carcinoma. Asian Pac J Cancer Prev 16: 7491-7496, 2015.

19. Nishikawa S, Konno M, Hamabe A, Hasegawa S, Kano Y, Fukusumi T, Satoh T, Takiguchi S, Mori M, Doki Y, et al: Surgically resected human tumors reveal the biological significance of the gastric cancer stem cell markers CD44 and CD26. Oncol Lett 9: 2361-2367, 2015.

20. Tseng JY, Yang CY, Yang SH, Lin JK, Lin CH and Jiang JK: Circulating CD133(+)/ESA(+) cells in colorectal cancer patients. J Surg Res 199: 362-370, 2015.

21. Shitara K, Doi T , Nagano O, Imamura CK, Ozeki T, Ishii Y, Tsuchihashi K, Takahashi S, Nakajima TE, Hironaka S, et al: Dose-escalation study for the targeting of CD44v cancer stem cells by sulfasalazine in patients with advanced gastric cancer (EPOC1205). Gastric Cancer 20: 341-349, 2017.

22. Wang W, Dong LP, Zhang N and Zhao CH: Role of cancer stem cell marker CD44 in gastric cancer: A meta-analysis. Int J Clin Exp Med 7: 5059-5066, 2014.
23. Takahashi RU, Miyazaki $\mathrm{H}$ and Ochiya T: The role of microRNAs in the regulation of cancer stem cells. Front Genet 4: 295, 2014.

24. Liu C and Tang DG: MicroRNA regulation of cancer stem cells. Cancer Res 71: 5950-5954, 2011.

25. Ma C, Huang T, Ding YC, Yu W, Wang Q, Meng B and Luo SX: MicroRNA-200c overexpression inhibits chemoresistance, invasion and colony formation of human pancreatic cancer stem cells. Int J Clin Exp Pathol 8: 6533-6539, 2015.

26. Yu D, Shin HS, Lee YS and Lee YC: miR-106b modulates cancer stem cell characteristics through TGF- $\beta /$ Smad signaling in CD44-positive gastric cancer cells. Lab Invest 94: 1370-1381, 2014.

27. Wu Q, Yang Z, Wang F, Hu S, Yang L, Shi Y and Fan D: MiR-19b/20a/92a regulates the self-renewal and proliferation of gastric cancer stem cells. J Cell Sci 126: 4220-4229, 2013.

28. Takaishi S, Okumura T, Tu S, Wang SS, Shibata W, Vigneshwaran R, Gordon SA, Shimada Y and Wang TC: Identification of gastric cancer stem cells using the cell surface marker CD44. Stem Cells 27: 1006-1020, 2009.

29. Xu H, Tian Y, Yuan X, Wu H, Liu Q, Pestell RG and Wu K: The role of CD44 in epithelial-mesenchymal transition and cancer development. Onco Targets Ther 8: 3783-3792, 2015.

30. Li LC, Wang DL, Wu YZ, Nian WQ, Wu ZJ, Li Y, Ma HW and Shao JH: Gastric tumor-initiating CD44 (+) cells and epithelialmesenchymal transition are inhibited by $\gamma$-secretase inhibitor DAPT. Oncol Lett 10: 3293-3299, 2015.

31. Zhang W and Li Y: miR-148a downregulates the expression of transforming growth factor- $\beta 2$ and SMAD2 in gastric cancer. Int J Oncol 48: 1877-1885, 2016.

32. Wang XH, Liu MN, Sun X, Xu CH, Liu J, Chen J, Xu RL and Li BX: TGF-beta1 pathway affects the protein expression of many signaling pathways, markers of liver cancer stem cells, cytokeratins, and TERT in liver cancer HepG2 cells. Tumour Biol 37: 3675-3681, 2016.

33. Hoshino Y, Nishida J, Katsuno Y, Koinuma D, Aoki T, Kokudo N, Miyazono K and Ehata S: Smad4 decreases the population of pancreatic cancer-initiating cells through transcriptional repression of ALDH1A1. Am J Pathol 185: 1457-1470, 2015.

34. Zhao S, Ammanamanchi S, Brattain M, Cao L, Thangasamy A, Wang J and Freeman JW: Smad4-dependent TGF-beta signaling suppresses RON receptor tyrosine kinase-dependent motility and invasion of pancreatic cancer cells. J Biol Chem 283: 11293-11301, 2008. 